\title{
Fighting Fires and Powering Steam Locomotives: Distribution of Control and Its Role in Social Interaction at Tangible Interactive Museum Exhibits
}

\author{
Loraine Clarke \\ University of St Andrews \\ St Andrews, UK \\ lec24@st-andrews.ac.uk
}

\author{
Eva Hornecker \\ Bauhaus-Universität Weimar \\ D-99423 Weimar, Germany \\ eva.hornecker@uni-weimar.de
}

\author{
Ian Ruthven \\ University of Strathclyde \\ Glasgow, UK \\ ian.ruthven@strath.ac.uk
}

\begin{abstract}
We present a video-analysis study of museum visitors' interactions at two tangible interactive exhibits in a transport museum. Our focus is on groups' social and shared interactions, in particular how exhibit setup and structure influence collaboration patterns. Behaviors at the exhibits included individuals focusing beyond their personal activity towards companions' interaction, adults participating via physical interaction, and visitors taking opportunities to interact when companions moved between sections of the exhibit or stepped back from interaction. We demonstrate how exhibits' physical configuration and interactive control engendered behavioral patterns. Systematic analysis reveals how different configurations (concerning physical-spatial hardware and interactive software) distribute control differently amongst visitors. We present four mechanisms for how control can be distributed at an interactive installation: functional, temporal, physical and indirect verbal. In summary, our work explores how mechanisms that distribute control influence patterns of shared interaction with the exhibits and social interaction between museum visitor companions.
\end{abstract}

\section{CCS CONCEPTS}

- Human-centered computing $\rightarrow$ User studies; Empirical studies in $\mathrm{HCI}$;

\section{KEYWORDS}

Social Interaction, Collaboration, Cultural Heritage, Public Displays, Tangible, Qualitative Methods, Video Analysis, Museums

\section{ACM Reference Format:}

Loraine Clarke, Eva Hornecker, and Ian Ruthven. 2021. Fighting Fires and Powering Steam Locomotives: Distribution of Control and Its Role in Social Interaction at Tangible Interactive Museum Exhibits. In CHI Conference on Human Factors in Computing Systems (CHI '21), May 8-13, 2021, Yokohama, Japan. ACM, New York, NY, USA, 17 pages. https://doi.org/10.1145/3411764. 3445534

Permission to make digital or hard copies of all or part of this work for personal or classroom use is granted without fee provided that copies are not made or distributed for profit or commercial advantage and that copies bear this notice and the full citation on the first page. Copyrights for components of this work owned by others than the author(s) must be honored. Abstracting with credit is permitted. To copy otherwise, or republish, to post on servers or to redistribute to lists, requires prior specific permission and/or a fee. Request permissions from permissions@acm.org.

CHI '21, May 8-13, 2021, Yokohama, Japan

(C) 2021 Copyright held by the owner/author(s). Publication rights licensed to ACM. ACM ISBN 978-1-4503-8096-6/21/05 ...\$15.00

https://doi.org/10.1145/3411764.3445534

\section{INTRODUCTION}

Museums and cultural heritage venues remain places tourists flock to on their holidays, and that local families, school groups and individuals visit in their localities. The cultural heritage sector is utilizing technology to attract visitors and keep up to date with exciting technology trends [37]. Visitors expect to see something special and unique in museums that they won't see or experience elsewhere. For many visitors, the museum experience includes spending quality time with companions [19, 23, 43]. However, what is deemed to be a successful interactive exhibit and interaction from the visitors' perspective can deviate from the museum's perspective [18]. Knowledge attainment and dwell time are frequently used as indicators of success, but the quality of visitors' interaction at interactive exhibits is less frequently considered [37]. An important and often overlooked factor contributing to visitors' experience is their social interactions while visiting the museum and interacting with exhibits [23]. This includes factors such as how companions are included in the activity and the patterns of collaborative action that emerge. Therefore, in our research we focus on how tangible interactive digital exhibits support social interaction and shared interactions for groups by examining visitors' interactions. While previous research outside of the cultural heritage context has suggested that different configurations of distribution of control can enable, encourage or enforce social interaction [7], there is limited research focusing on how interactive exhibits distribute control among group members and on the role of the configuration of distributed control in companions' shared interactions. By studying video recordings of visitors' conduct at two interactive exhibits in a museum, this research explores how mechanisms that distribute control influence patterns of social interaction between companions who interact with exhibits together.

We here highlight the benefits of distributing control between members of a group to enable greater active co-participation and, for instance, to ensure sharing of control. We suggest the deliberate distribution of control of digital content between companions as an explicit design strategy for exhibit design in cultural heritage and entertainment contexts. The identified benefits include supporting shared interaction for members with a system while at the same time encouraging direct social interaction between companions. A key contribution of our work is the unpacking of distributed control regarding a variety of strategies or mechanisms for doing so, that is: functional, temporal, physical and indirect means of distributing control. These mechanisms open up opportunities for future research and installation design. 
We conducted a study of museum visitors' shared interactions with companions at two tangible interactive exhibits on display at the Riverside transport museum. The exhibits have several features in common such as supporting (and requiring) multiple companions to interact, allowing interaction with several tangible controllers and encouraging visitors to take on roles related to the artefacts the exhibits are connected to. Taking an 'in the wild' approach to the research, visitors' interactions and behaviors were captured using video-audio equipment. Analysis focused only on family groups and was conducted based on interaction analysis and thematic analysis [11, 24, 41]. Main themes of analysis were how visitors coordinated their actions with companions while interacting with the exhibit, the specific patterns of physical movements that visitors engaged in, and adult participation in the activity, in particular physical-manual interaction with exhibits along with children. We identified the configuration of exhibits to be a major source contributing to these behavior patterns.

We conclude with a discussion of three aspects from reflecting on our observations, focusing on distributed control as a specific design feature of exhibits: Firstly, we propose that the configuration of exhibits (specifically by different ways that control is distributed between companions) influenced social behaviors. We suggest that distributed control can lead to alternating sequential interaction and actions within groups, creating situations where visitors rely upon their companions in order to successfully interact with an exhibit. Secondly, we discuss benefits of this reliance on companions and of alternating actions, in particular, that visitors do not focus solely on themselves, but pay attention to each other. Finally, we discuss how the configurations of distributed control offered alternative positions and perspectives for companions as well as the value this added in supporting co-experience and fostering the inclusion of companions in the activity. We identify four central ways that such configuration can be implemented.

Previous research has put forward design principles and sensitivities to promote social engagement and co-participation [30, 57]; we contribute a detailed understanding of the ways in which the design of an installation distributes control between companions. We distil this into core mechanisms of the distribution of control and how they play a role in the social interactions which unfold between companions using the interactive exhibits.

\section{BACKGROUND}

\subsection{Social Interaction in the Museum Context}

Research regarding the museum visitor experience has traditionally focused on knowledge attainment [23, 29]. Far fewer studies focus on the social dimension of the museum experience, despite research highlighting the significance of social interaction in people's experience, engagement and connection to the narratives of installations [5, 10, 14, 19, 23, 45, 51-53].

Visiting a museum is a highly social experience. Most visitors attend museums with friends, family or groups [2, 23, 35, 43] and even if visiting alone, observing other visitors brings a social dimension to the museum experience [64]. Visiting a museum with companions gives visitors the platform for spending time together [19, 51]. People often visit museums for social reasons, to spend quality time together and consolidate their bonds [19]. Furthermore, visitors influence each other's behaviors such as leaving exhibits earlier than they might want to in order to keep up with a group [62]. Parents might follow younger children around the museum, allowing them to lead the visit [23]. Individuals with more knowledge about the exhibits or museum might direct the rest of the group. Family groups may separate and re-group or stay together during their visit moving around the space [21]. Family members often move through the museum as a unit, interacting with each other, enjoying the museum together, helping each other to learn and explore [44].

Companions engage in a wide range of social behaviors and situations while visiting a museum. These include; commenting and laughing together at content [50]; seeking or sharing information [6]; co-creating fictional stories together [60]; negotiating turn taking [8]; sharing emotional reactions [67]; observing others interact [5, 50, 64]; suggesting ideas and creating content together [50]; physically sharing control of an object by pushing or moving it in the space at the same time $[15,35]$; mediating other people's interactions [53]; or sharing by pointing out aspects to each other [6, 36, 47]. Ultimately, the social aspect is a core element of the museum experience [23] and it is important to understand if and in what ways hands-on interactive exhibits in museums support the social dimension of the museum experience.

\subsection{Technology in Museums Supporting and Hampering Companions' Social Interaction}

Museums and public facing cultural venues increasingly utilize technology to create interactive experiences for their audiences. However, these technologies often influence the social context. Here, we highlight previous research that identified aspects which either support or hamper social interactions in museums.

Previous research concerned with social interaction at interactive exhibits has explored two key aspects. The first is the level of interactivity that an exhibit can support for multiple members of a group, which can be understood as shared interaction [32, 39, 60, 67]. The second aspect is the level and type of social interactions that companions engage in with each other while using interactive exhibits [30, 62, 67]. A challenge for many multi-user interactive exhibits is balancing interactivity for multiple people while also fostering social interaction between companions. A detailed and nuanced perspective of supporting participation, interactivity and social interaction is understanding of co-participation [30]. Coparticipation refers to the ways companions participate in an activity and the "organisation of action at the exhibit-face" [30]. It considers social interaction beyond verbal communication, including bodily orientation, gesture, gaze and the visible manipulation of exhibits. Hindmarsh argues that such behaviors are "critical to the ways in which participants organise their collaborative appreciation of exhibits and constitute the sense and significance of the exhibit" [30] p.31. It is important to recognize the understanding that co-participation refers to participation in the activity surrounding interaction with an exhibit as well as interaction which triggers manipulation of digital content.

Some interactive museum technologies isolate visitors from each other, effectively creating barriers for social interaction [28, 37, 63] such as audio guides, individual VR headsets or single user 
exhibits. However, a variety of work has explored ways to support the social dimension of companions' museum experience. These range in levels of interactivity and social interactions between companions. As an extreme example, Warpas removed interactivity from an exhibit design in a bid to encourage social interaction between companions [67], merely triggering audio-visual content communicating narratives relating to the artefacts on display. This elicited highly social events between companions who focused on the common object and content, sharing their responses in conversation [67].

Adding a single means of interactivity with digital content (as done by traditional single user exhibits) has been associated with limited social interaction between companions [28, 35, 63, 64]. Visitors can end up merely observing their companions' interaction with an exhibit, arguably creating a barrier for social engagement. However, observing others interacting with exhibits can also enable visitors to learn what the exhibit is about and how to use it, revealing the functionality of different parts [5, 26, 30, 64], before joining in on one's own initiative [48]. Moreover, members of a group may suggest what their companions should do next, commenting on the ongoing activity, and sharing ideas [50, 60]. Observing performative interactions can be particularly enjoyable and social [40, 46, 54]. However, when companions are limited to just observing interaction, the opportunities for collaboration, discussion and sharing interaction are limited and offer impoverished co-participation [27,30]. Individuals can become preoccupied with their own personal interaction, hampering capacity for social interaction. At these exhibits, interactivity has increased for one person, but group members are not in an equal position.

Many interactive exhibits enable multiple visitors to interact alongside one another [57]. Typically, this is achieved by adding additional means of interactivity. This increases the complexity and variation of how exhibits can be configured. Common strategies include allowing for simultaneous (but unrelated) interaction, interlinking activity of individuals, group work strategies that require concerted collaboration, or competitive activities. This has contributed to a wide variety of multi-user interactive museum exhibits such as; large multi-touch interactive tabletops where multiple people can browse and explore interactive visualisations [9, 30,31], can play competitive quiz games [34] or simulation games [32], exhibits which provide multiple individual stations for visitors to interact with [27, 35], as well as tabletop tangible interfaces where digital content is manipulated by moving physical objects on the surface $[17,42,69]$, where in some cases, placing tangible objects close to other objects triggers digital content [57], and exhibits where individuals in the group have different controllers to use together to solve puzzles or tasks $[49,56,59,66]$.

While enabling multiple visitors to interact alongside one another may support high levels of interactivity for multiple individuals, it does not automatically result in rich social interaction [7] or a positive visitor experience [1]. One person's interaction can interrupt others [31]. Exhibits with multiple individual stations (even if located close together) can result in visitors focusing on their own interaction and only occasionally glancing or calling out to companions nearby [27]. Companions can be completely absorbed in their own activity with little time, attention or incentive to engage socially with others. Exhibits that encourage energetic and flamboyant moves may limit visitors' focus to their own movements and interactions [57]. Engaging individuals in simultaneous parallel interaction has even been criticized for hampering direct communication or interaction between active users [60]. Co-visitors may not notice and react to each other's activities, and not work towards a common goal. Thus, albeit two key design guidelines for engendering collaborative activities are to allow for simultaneous action and to provide multiple points of interaction [33, 57], these are not sufficient. Design recommendations have included providing multiple controllers, interlinking the results of visitors' interactions in a way that adds value, but does not interfere [57], and providing rewards for joint coordinated actions and a joint goal $[7,12]$. Nevertheless, we still know little about how to design for social shared interactions and about which social behaviors might be supported through specific design features or strategies. Our work contributes to closing this gap and uncovering design strategies.

Institutional research in museums still tends to focus on quantitative visitor surveys, understanding demographics, visitor motivation and interests [37]. Importantly, most museums simply lack staff and funding for detailed evaluations. Furthermore, it appears that summative evaluation is rarely seen as an opportunity for reflection and learning [18], meaning that exhibition evaluations rarely extract transferable insight or result in redesigns. Moreover, the way the industry sector is organized contributes to problems in accumulating knowledge. Usually, there is fixed funding with tight budgets for new exhibitions, with no money dedicated to post-hoc assessment. Therefore, in this practitioner domain, detailed evaluations are rare, and the community largely depends on academic research to provide analysis, identify and name factors.

\subsection{Configurations of Distributed Control}

We now discuss prior research that has focused specifically on the challenge of designing for distributed control both within and outside of the museum context. While having multiple access points [38] allows multiple people to be involved in interaction, this alone does not necessarily result in social interaction [7]. Prior research has indicated that the configuration of inputs and outputs influences how companions interact with each other [30,55]. Benford et al. [7] discuss how technology may be used to support collaboration, distinguishing three different levels. These can be imagined on a three-point scale from enabling to encouraging to enforcing collaboration [7]. 'Enabling collaboration' (lowest level) provides affordances for fluid collaboration and ensures that the technology does not prevent collaboration [7, 57]. At the next level, technology may 'encourage collaboration' by creating invitations to collaborate. For example, there are benefits from having others join in, such as interaction and digital content becoming more interesting. This is similar to Snibbe and Raffle's [57] recommendation that while interaction should become richer as more people interact, an exhibit needs to also function for a single user. Some previous multi-user exhibits have explored this strategy [7] of rewarding joint activities, but do not enforce them, allowing individuals to pursue their own individual interests [12]. Companions joint coordinated activities can unlock 'enhanced functionality' such as otherwise inaccessible digital content $[7,12]$. At the strongest level, technology enforces 
collaboration; at this level interacting alone may not be possible or may be ineffective. This enforcement can occur through built-in rules of collaboration, such as enforced turn-taking. For instance, installations may require everyone to select the same option on their own panel for a game to proceed, thus requiring all to agree; or installations may provide each interactor access only to certain parts of the interaction resources, and thus creates a situation in which interactors must work together and rely on others. How control is distributed between companions in all three of these levels varies in its configuration and influences the social activities which companions engage in.

Hornecker et al. [38] investigated qualities relating to the shareability of interactive systems for collocated groups. Shareability relates to Benford et al.'s [7] level of 'enabling collaboration'. Hornecker et al. [38] outlined two overarching ideas: entry points, and access points. Entry points invite people to participate by stimulating their curiosity and encouraging them to become involved. Entry points are linked to qualities such as visibility, providing an overview, turning collocated people's attention to others, and tempting them to interact. Access points enable individuals to be actively involved in group activity by helping them understand how people interact, knowing how to join in, allowing them to manipulate digital content, and enabling them to fluidly share the interaction back and forth with others [38]. Hornecker's [38] model thus identifies a range of characteristics of systems that enable and (at least partially) encourage collaboration.

Several publications have advocated for equal access to controllers (in particular by providing multiple controllers) and equal participation [33, 38, 55]. Equal access to controllers and digital output can encourage collective meaning making and discovery of a story [22]. On the other hand, a number of studies have suggested that privileged and limited viewpoints prompt creative and playful social behaviors in trying to understand the connections between the input and digital content [30]. A separation of inputs and outputs can also prompt social activity. 'Ambient Wood' was one such scenario which provided the input and output on separated mobile devices [56], creating a division of labour, that encouraged and required teamwork (thus being closer to the 'enforcing collaboration' level), where children relied on each other to complete the activity (see also [3, 68]). Some exhibits have explored a structured and enforced collaborative design where sequential interaction or joint interaction between companions is required [66].

Prior research has developed design principles and sensitivities concerning social engagement and supporting different forms of co-participation [30,57]. Our research differs in that we explicitly unpack the ways in which control is distributed between companions and how this relates to social interactions between companions that use the exhibits together. Very few studies [7, 56, 66, 69] focus on the type of exhibit configuration which we found at the two installations we focus on here, where there are multiple tangible controllers functioning in different ways, physically separated from each other and attached to the exhibit, that need to be utilized at specific moments, which form an interconnected system. Here, we contribute to understanding this design space of distributed control, by studying two cases of distributed control, that require the collaboration of at least two users. Our analysis brings a new perspective to understanding distributed control between companions through four distinct mechanisms: temporal, physical, functional and indirect verbal control, and how these play a role in the social and shared interaction which unfold between companions at interactive museum exhibits.

\section{STUDY OVERVIEW}

The research study took place at the Riverside Transport Museum, in Glasgow, which opened in 2011. The museum is a distinctive and popular attraction known for its innovation in adopting new technology with several interactive digital exhibits encouraging hands-on and active visitors' experiences while complementing the museum's traditional exhibits. An aspect of the visitor experience prioritised by the museum is to support social experiences, aligning with the focus of this research. Our study specifically focuses on the social interactions and behaviors that companions engage in while they interact with interactive exhibits that distribute control between companions.

Collaborating with the museum involved discussions with curators, observations in the museum, interviews with staff members, understanding the museum's documentation and design process relating to the interactive exhibits and an in-depth qualitative empirical study of visitors' interactions at two particular interactive exhibits, utilizing video-audio research methods. We selected these two exhibits from over 40 interactive stations distributed across the museum because they require collaboration and were successful examples for this, while not copying patterns of existing games. The findings presented in this paper are drawn from analysis of video-audio data of visitors' interactions with these exhibits.

\subsection{The Exhibits}

The two exhibits focused on were 'The Glen Douglas Steam Locomotive' in Figure 1 and 'The Fire Fighter' in Figure 3. The interactive exhibits have a number of similarities and were selected for in-depth study because of these characteristics. They both support multiple people interacting simultaneously and they provide several physical controllers supporting tangible hands-on interaction. Both require the interaction of at least two people and the coordination of their activities. These aspects are central to our overarching research agenda. In addition, both are large exhibits with controllers located at least 2 metres apart from each other. At the Glen Douglas, visitors can simulate running a steam locomotive, adding coal and water to the boiler while regulating the steam pressure (see also[13]). At the Fire Fighter exhibit, visitors extinguish fires using a hose at the top of a ladder, and by turning a wheel next to the ladder, position the ladder in front of the fires as they appear in the windows of different buildings. For the sake of brevity for the rest of the paper, the exhibits will be referred to as GD for 'The Glen Douglas Steam Locomotive' exhibit and FF for 'The Fire Fighter' exhibit.

GD was designed to illustrate the different processes required to power a steam locomotive. The real steam locomotive built in September 1913 is placed alongside the interactive exhibit (Figure 1 Left). Visitors simulate operating the steam engine by adding water and coal at station 1 (Figure 1 right), while regulating the steam pressure at station 2 (Figure 2 left). If visitors manage to balance these successfully, a physical locomotive wheel model moves at the opposite end of the exhibit and the noise of a steam locomotive can 

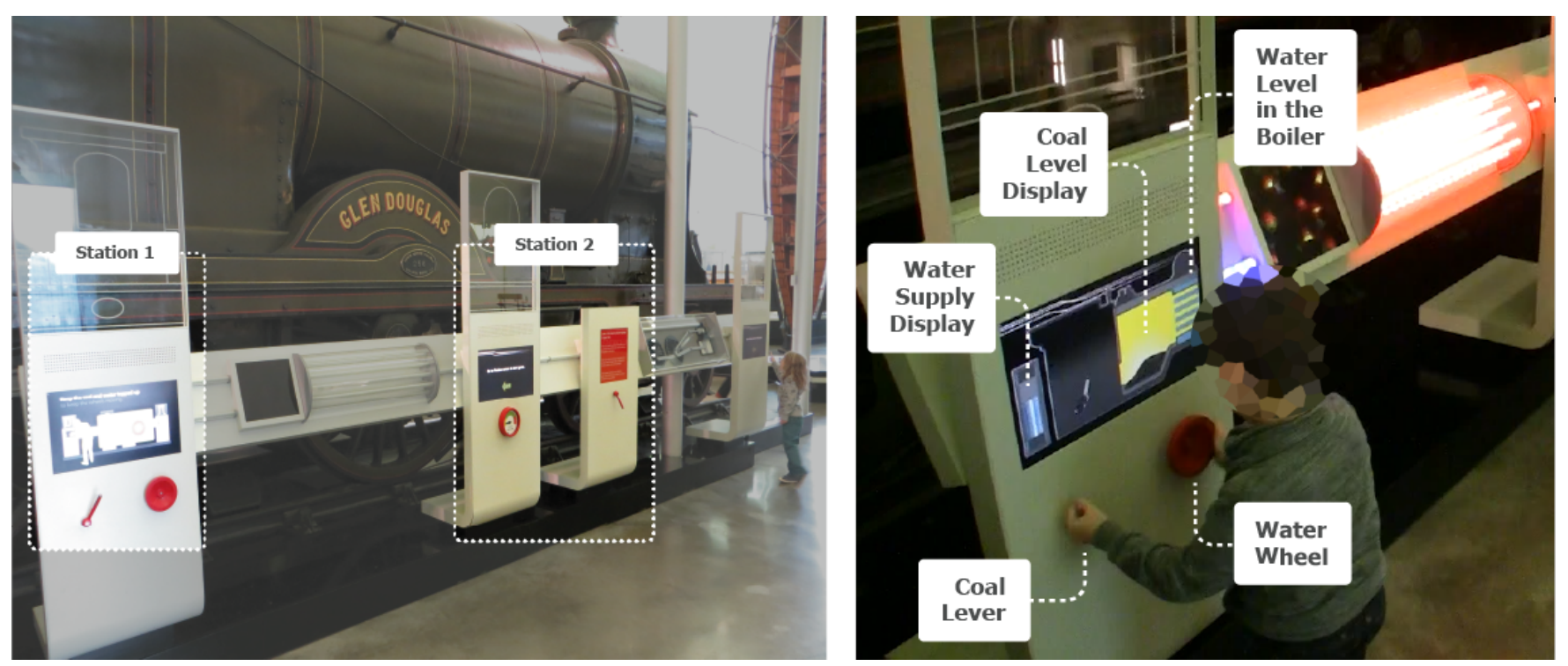

Figure 1: Glen Douglas Tangible Interactive Museum Exhibit \& Key Parts of Station 1
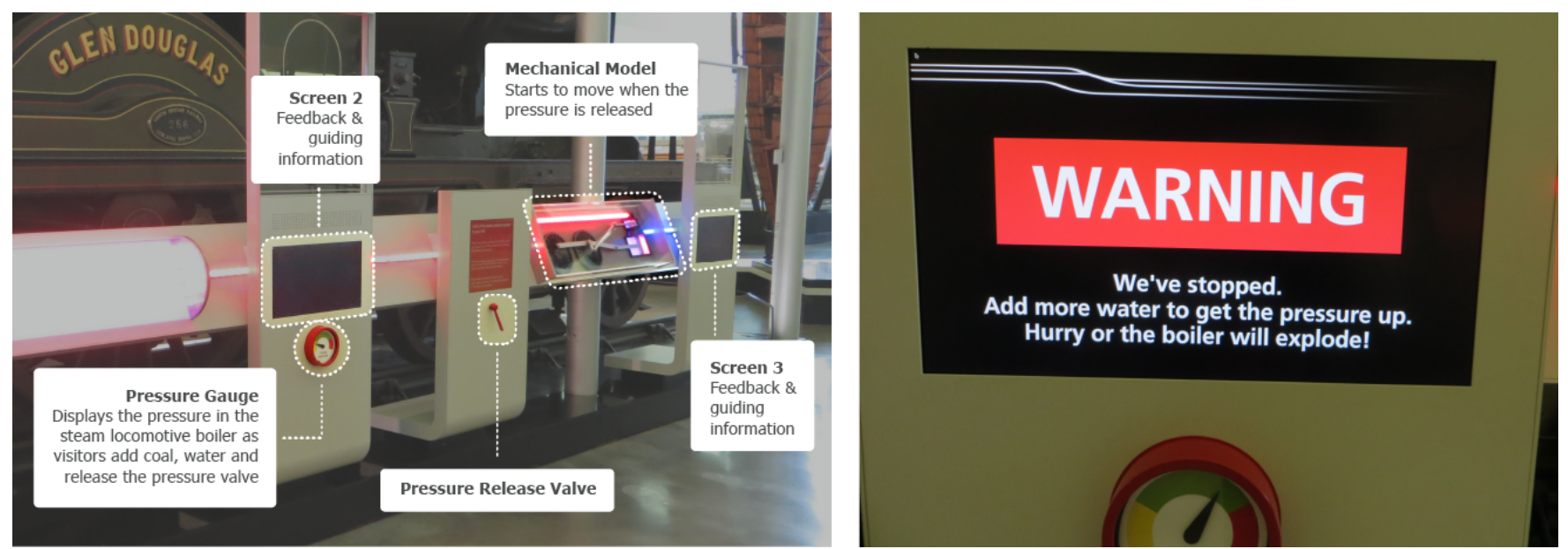

Figure 2: Key Parts of Station 2 \& Example messages displayed on screen 2

be heard. To interact with GD, there are two interactive stations. Station 1 has a lever to add coal, a wheel to add water and a screen depicting the inside of the engine (Figure 1 right). Station 2 has a lever, a pressure display, a screen displaying messages and visual feedback, and a dynamic model of a steam locomotive (Figure 2 left). At the far end of the exhibit there is a third screen displaying messages and feedback as visitors interact. While visitors add coal and water at station 1, guiding messages appear on screen 2 and 3 (Figure 2 right). The messages inform visitors when to add or stop adding coal and water to the engine (Figure 2 right). It is impossible to handle this successfully alone. The guiding messages are located far away from the coal and water controllers at station 1 and the activity is under time pressure, requiring quick reactions. The exhibit was intentionally designed to emulate and illustrate the teamwork involved in running a steam locomotive.
The second hands-on hybrid interactive exhibit called FF was designed for children aged under five. Located beside a real fire truck (Figure 3 left), the exhibit enables visitors to act as fire fighters, replicating the arrangement of ladder, fire hose and turntable the ladder sits upon, on a real fire truck. Visitors work with partners to manoeuvre the ladder and put out fires in buildings. There are two controllers: a fire hose at the top of the ladder, and a wheel to move the ladder, as illustrated in Figure 4 (left). Fires appear in different windows of buildings (Figure 3 right). The buildings' style imitates the local architecture. Visitors assuming the role of 'ladder operator' at the bottom of the ladder can turn the wheel to manoeuvre the ladder from left to right, helping to position it towards the fire (Figure 4 left). At the same time, another visitor taking the role of 'fire fighter', at the top of the ladder can point the hose at the fire to put it out. Pressing a button on the hose causes whooshing sounds. 

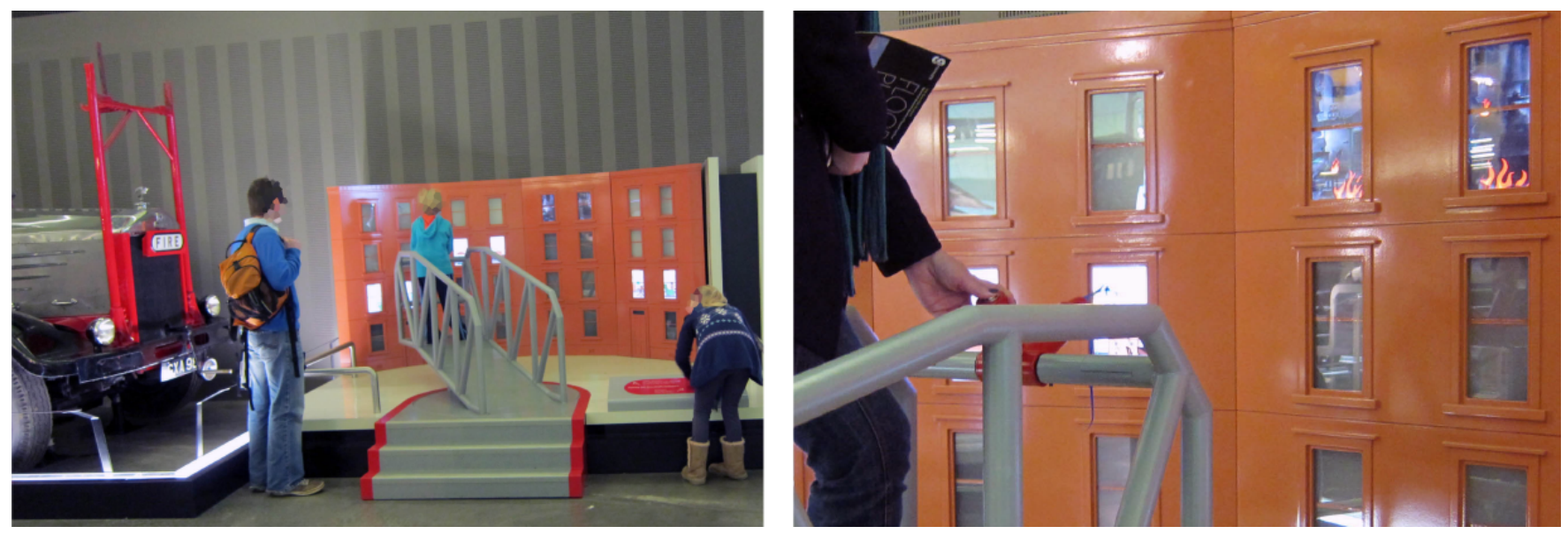

Figure 3: Fire Fighter Tangible Interactive Museum Exhibit
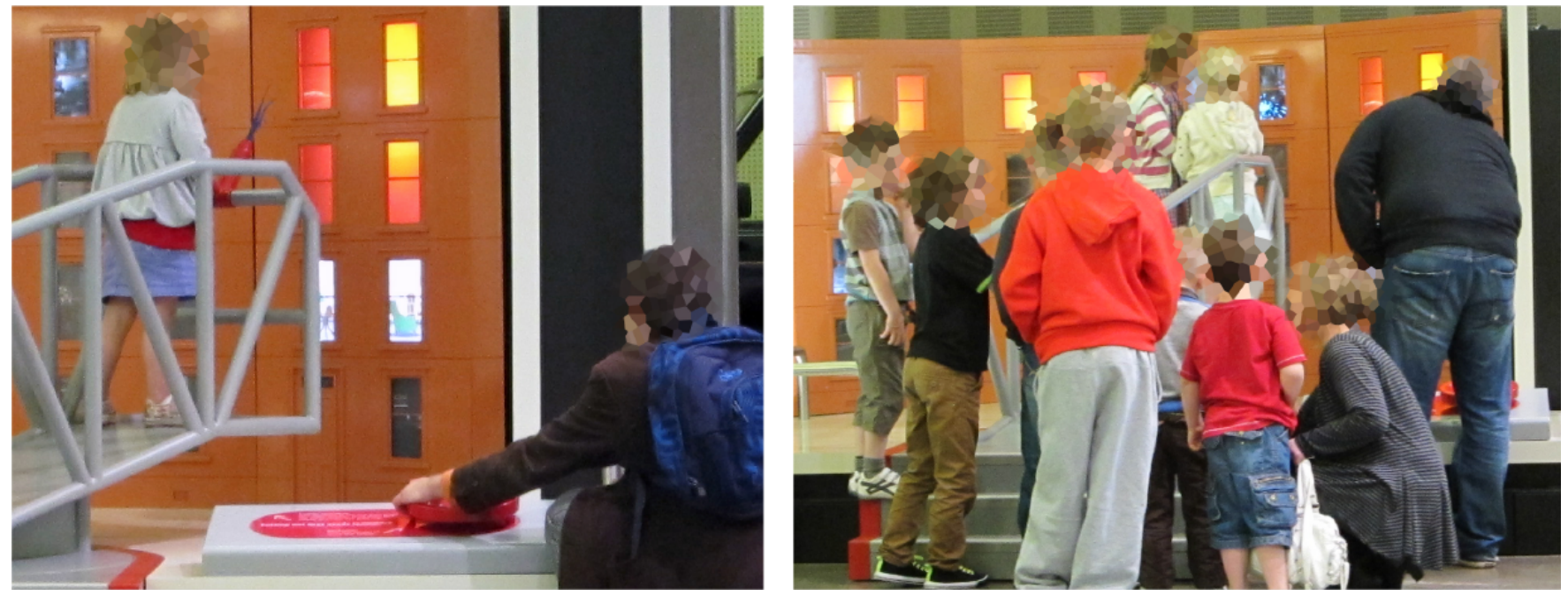

Figure 4: Controllers at the Fire Fighter Exhibit \& Queues to interact

Pieces of transparent material protruding from the hose are blown with a fan to emulate water spraying from the hose (Figure 4 left). The exhibit continues in a loop with fires appearing in the windows of buildings and visitors extinguishing them, and fires coming up again at different windows, spreading out.

For both installations, the museum identified the narratives and activities associated with the real artefacts (in their collections) as inherently collaborative and appropriate (a good match) for the activities the museum aimed to support for the respective audiences (adults and teenagers versus families with young children). Therefore, the design brief set for these installations stressed collaborative, team-based and task-oriented activity replicating the task structure of the origin activity. While we are aware of this design brief, our aim in this work is not to validate design intentions, but to unpack situated conduct and practices so as to inform future design.

\subsection{Study Design and Methodology}

In this research, we examine visitors' interaction at interactive exhibits and the patterns of interaction between companions while using the exhibits. In particular, we study the influence of the setup of an installation on these collaboration patterns. This was investigated using a video-based interaction analysis approach, oriented by principles of interaction analysis [41], video analysis [25], and thematic analysis [11,24], in an open-ended, emergent process.

Observation is a central method to understand visitor behavior, since actual conduct of visitors "may sometimes critically differ from what people report in interviews" [37]. Video-audio recording is highly effective for capturing sequences of events, people's behaviors and their interactions in a way that does not disrupt natural behaviors [28, 48, 65, 69]. Video captures how a situation unfolds, the actions between people, the sequential order of actions, and enables the researcher to uncover how people organise their actions in relation to others and their environment [28]. As video 
recordings can be repeatedly viewed, video observation is suited especially for fast-paced and multi-person situations.

Video analysis for these reasons has been a popular method for investigating the interaction of groups with museum exhibits. Meisner et al. [48] found when visitors at a science center observed others' interaction with an exhibit, this enabled them to understand the activity in their own time, before joining in. Micro-analysis of video-audio data by Hindmarsh et al. [30] revealed playful social interactions between visitor companions, and highlighted the role of non-verbal 'co-participation', through observable bodily orientation, gesture, gaze and visible manipulation of exhibits, which contribute to people's sense-making and to social coordination. A micro-analysis of visitor interactions with two versions of the Jurascope (a telescope-like AR-view and a large screen relating to artefacts in the room) revealed contrasting conversation patterns and inability to communicate with peers from the telescope, as well as how visitors would frequently 'index' back and forth between objects in the room and related depictions on-screen [36]. Therefore, we approach our research studying visitors' interaction with the exhibits and the social interactions through the analysis of video-audio data.

Video-audio data was recorded during a week of school holidays. With a priority to create minimal disruption to natural behavior, recording equipment was used to capture visitors interacting with the exhibits. According to legal regulations at the time, video-audio recording could be carried out without explicitly inviting visitors to participate in the study, as the museum is a public space. The data collection approach was discussed and approved by the museum and the research was approved by the relevant ethics committee of the University of Strathclyde. Several signs surrounding the exhibits informed visitors of the study, its purpose and gave information on how to opt out, if they wished to do so. Several cameras as well as additional audio recording equipment were distributed in fixed locations at the exhibits for 2 days. A total of 17 hours and 28 minutes of video-audio data was recorded.

Our research is concerned with determining general patterns of interaction and their relation to features of the exhibits, leading to design-relevant recommendations. Our intent and approach is thus more closely related to interaction analysis [41] and thematic analysis [11, 24], than to an ethnomethodological approach [25], which would focus on single incidents. Given our research does not focus on people's motivations and subjective experience, we relied solely on (video) observation.

Our analysis process involved the following steps: preparing data, overview review, creation of a data catalogue, filtering the data corpus to identify a relevant and valid data set for analysis, transcription and iterative coding of the data set, for FF creation of visualization and finally development of themes based on researchers' reflective interpretations of the data [11, 24, 41, 48].

Preparing data included combining the different camera views into an integrated view with timestamps for the Glen Douglas Steam Locomotive exhibit, given its complex setup. Following initial viewing of the material to familiarize with it, randomly selected snippets were reviewed while noting observations, early insights, and indication of potential patterns. This resulted in a reference list of potential foci and questions which then guided further analysis [25]. For overview, a reference catalogue of the data corpus was created. The criteria for inclusion in the (filtered) dataset for further analysis included: quality of video-audio data, family groups that physically interact with the exhibit for more than 30 seconds and spoke English. We interpreted groups with adults and children to be families. Groups comprising one or more families were included.

As FF had a constant stream of groups with children, the first hour of video-audio data was selected as a random sample for analysis. GD did not have the same constant attendance. Thus, for GD, the data set contains all family groups with at least two children and one adult, resulting in a dataset of 9 groups. Transcripts of interaction, containing dialogue and description of manual interaction, were generated for 9 groups compromising 43 visitors at the GD and for 8 groups at the FF exhibit compromising 29 visitors. The data set was analysed using a combination of thematic analysis $[11,24]$ and interaction analysis [41]. Codes were developed in a process of open coding in parallel with transcriptions. Reflections, comments and possible codes were noted during transcription. The codes were iteratively developed to cluster similarities, breaking codes up when they became too broad or merging similar codes $[11,24]$. Transcripts, codes and themes were frequently discussed in the author team to validate decisions and to sharpen focus.

Furthermore, visualizations were generated of individual group members' physical interactions with different parts of the exhibits over the time a group was at the exhibit. For FF, which had only two controllers, the visualisations were successful to support analysis. However, for GD with its multiple controllers and distributed activity, the visualisations produced less insights than transcribing and coding group interactions, while taking high effort to create. Therefore, data visualisations were only used as an analytic tool for researching group interaction at FF. 28 groups consisting of 79 people made up the visualization dataset of visitors interacting at FF over one hour.

\section{OBSERVATIONS: COMPANIONS' SOCIAL AND SHARED INTERACTION}

Here, we discuss our findings regarding patterns of visitors' social interactions with their companions and shared interaction with the exhibits. Part one discusses companions' coordinated actions while interacting with exhibits. Part two presents visitors' typical physical movements patterns during interaction. Finally, we discuss adult participation in activity and their physical interaction with the exhibit along with children. Vignettes from each exhibit are presented with pseudonymous names used throughout. Note that ages for child participants and family relations in vignettes are hypothetical guesses, based on behavior and appearance. Throughout the analysis section we will already indicate in brackets the type of control distribution in place which will be presented in detail in the discussion section.

\subsection{Coordinating With and Turning Attention Towards Companions}

While interacting with both exhibits, visitors engaged in various coordinated actions with their companions such as relaying information from one part of the exhibit to a companion at another section, pointing out what to do, waiting for a companion to finish their action before acting themselves. At GD, visitors' coordinated 

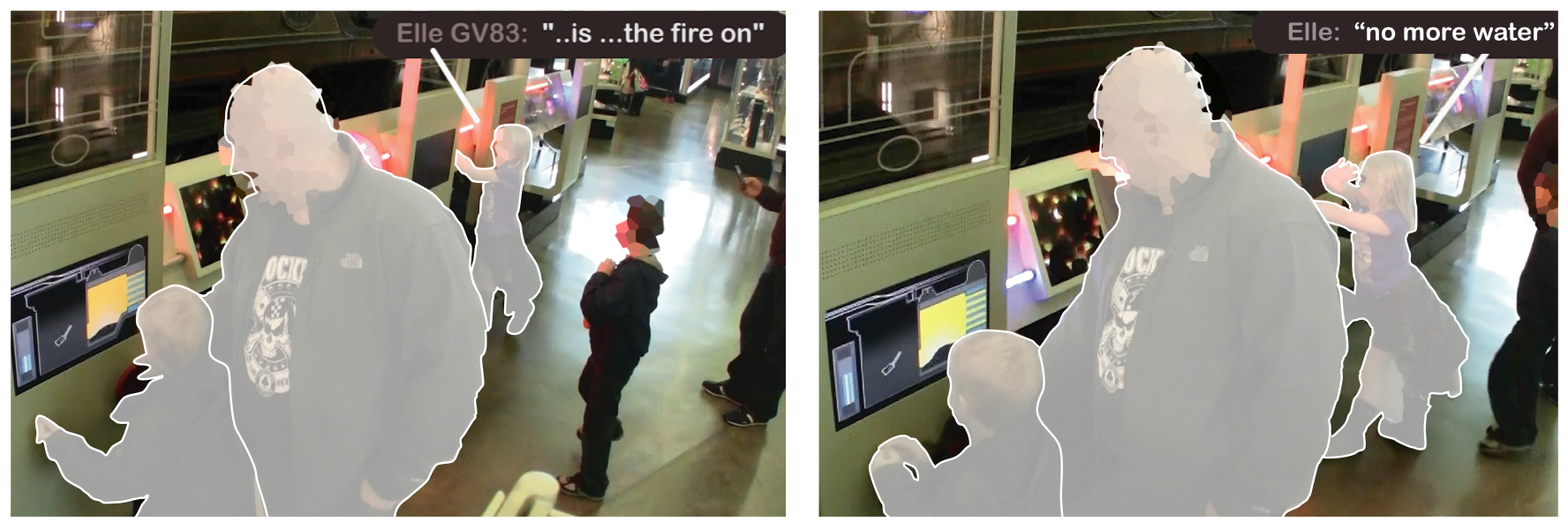

Figure 5: Elle shouts: "is the fire on" \& later instructs them: "no more water"

actions were typically related to the guiding information on screen 2 and 3 (Figure 2 shown above). At FF, companions' coordinated actions were predominantly related to turning the tiller wheel (Figure 4 shown above) to manoeuvre the ladder to a desired position. During such coordinated actions, visitors turned their attention away from their own personal interaction towards their companions.

The following vignette describes a family group coordinating their actions while interacting with the GD. The group consists of Steve (6), Elle (8), Mum, Dad and five other children who were not active during the vignette. Barry, a child from another group who has used the exhibit many times, watches the group.

\subsubsection{Vignette 1.}

Dad and Elle approach GD. Steve (at station 1) has already been using GD with Barry, a boy from a different group. During the instructions, Dad watches and tries to figure out and explain what to do while Elle moves up and down the exhibit, touching and looking at all the different parts of the exhibit. Elle looking at screen 2 shouts out "is the fire on" as she explores the exhibit. Dad and Steve keep their focus on station 1 (Figure 5 left). Dad tries to use the controllers alongside Steve at Station 1. Elle continues paying attention to the parts of the exhibit away from Station 1 at the pressure lever controller (Figure 5 left).

Steve informs Elle that she's supposed to tell him when to add water. Elle responds to his request, starting to move towards him. She appears to notice the information on screen 2 and begins to read it out loud. She's moves towards Steve at station 1, telling him to "add water now". Dad encourages Steve to keep turning the handle. Reading out screen 2, Elle communicates "Please stop" she pauses briefly and continues speaking "... add more water".

Elle moves to stand beside the others at station 1 telling them "hurry before the boiler explodes". Elle repeatedly moves directly between the instructions on screen 2 and her companions (Steve and Dad) at station 1.

Elle standing at screen 2 relays the next instruction to them "no more water" and holds up her hand (Figure 5 right). At this moment Dad now appears to realize the connection between the information at screen 2 and the coal and water controllers that
Steve is using at station 1. Dad repeats the information. They continue with Elle telling them next "you need to add coal now".

In total, the group went through the interaction process for the exhibit six times. Initially, Elle did not relay information from screen 2 to Steve and spent her time exploring the exhibit. After Steve informs Elle how she can help him to get the locomotive running, she starts to relay the information (indirect verbal distribution) on screen two to help Steve use the controllers at station 1 (functional and physical distribution) at appropriate moments (temporal distribution). The group now coordinates their actions, socially interacting with each other while also sharing the interaction with the exhibit. Elle, Steve and Dad pay attention to what each other is doing, communicating back and forth between the two stations (Figure 5 right). However, maintaining coordinated actions is difficult and the group's interaction enters the final stage where the exhibit fails regardless of their coordinated actions as the fire becomes choked with too much coal.

Similarly, at FF, visitors coordinated their actions with companions in different ways such as searching for fires in the windows together, pointing out fires, requesting the ladder to be moved, moving the ladder in response to their companions' requests and turning their attention to their companions at the other controller. These behaviors frequently transpired while groups used FF. The next vignette details a family group coordinating their actions at FF. The group consists of Mum, two toddlers Sally and Rosy, a girl called Amy (age 7) and a boy called Mark (6). We join the group as they wait for a fire to appear in the window.

\subsubsection{Vignette 2.}

A fire appears in the window of the building. Sally (standing beside Mum near the wheel) points to the fire shouting "hhoooo". Amy standing on the ladder holding the hose, turns away from the building and looks directly towards them. Mum starts to point out the fire too "oh look look, there you go".

A man from another group waiting with his grandchild starts to point at the fire as well (Figure 6 left). Amy (on the ladder with the hose in her hand) looks at the fire and starts rocking on the ladder from side to side appearing to try and move it. The boys 

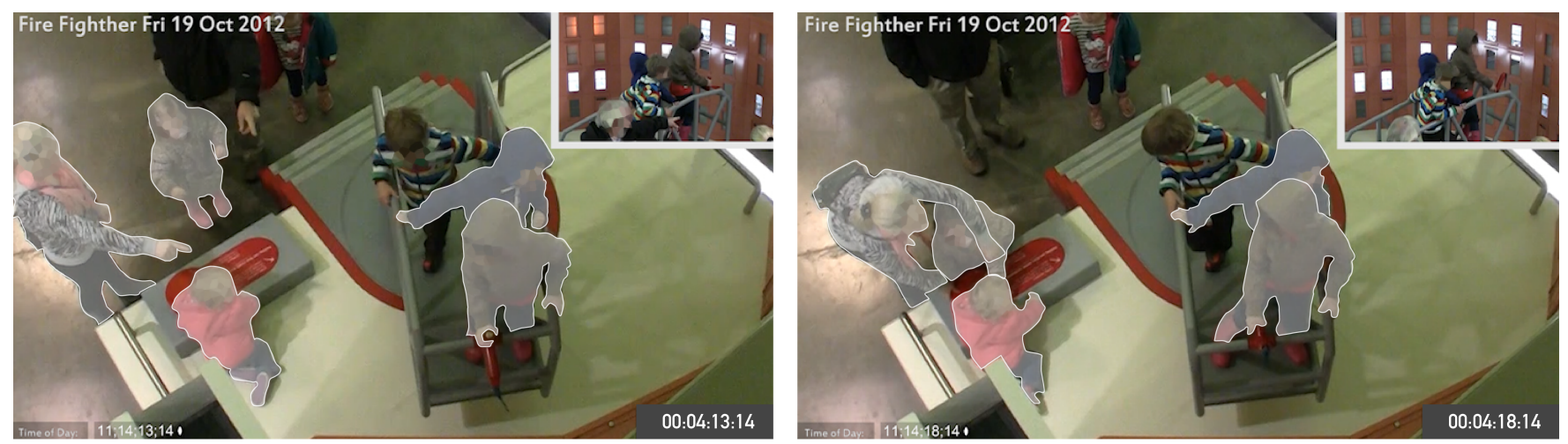

Figure 6: People pointing \& Mum turning the wheel

on the ladder with her try to see around her at the fire too. Amy asks to be moved on the ladder "Mummy I said ...".

Mum is semi-distracted talking to the stranger while using the wheel "...trying to steer it but it doesn't seem to do anything" (referring to the wheel).

Rosy is already trying to turn the wheel. Mum responds to Amy's request on the ladder and starts to move the ladder using the wheel, taking over from Rosy (Figure 6 right). Mum: "right, watch" as she starts to use the wheel with Rosy, to move the ladder for Amy to put out the fire.

The vignette highlights a recurring pattern where visitors coordinate their actions together. A child points out the fire, sparking other group members to point to the fire as well. The hose operator turns their attention to companions and communicates (indirect verbal distribution) with those at the wheel (physical distribution), requesting they move the ladder into a desirable position (functional distribution). They respond and an adult moves the ladder (temporal distribution). The event included several members of the group sharing the overall activity. Pointing out fires and suggesting where to move the ladder were frequent activities companions engaged in. Another prominent behavior the vignette reveals is children on the ladder at the hose turning away from the exhibit and looking back towards companions at the wheel, requesting help (moving the ladder).

The coordinated behaviors observed at both exhibits involved people interacting in a way which focused their attention not solely on their own interaction with the exhibit, but also on their companions.

\subsection{Movement in Space and Exchanges Between Companions}

At both exhibits we could observe particular patterns of physical movements by visitors over the course of the group's interaction. Companions moved to different positions and swapped back and forth in some cases, sharing interaction with a companion.

At GD, the most frequent movement was visitors moving between station 1 and 2 (physical and functional distribution). This often involved a visitor stepping back from interaction and moving to overlook the entire exhibit, to observe what their companions were doing, or review information shown on screen 2 and relay the information to companions at station 1 (indirect verbal distribution). At $\mathrm{FF}$, the most frequent pattern was visitors moving from the hose controller to the tiller wheel controller (physical and functional distribution) after they finished using the hose, switching roles. The reverse pattern of movement occurred only half as often. This was also due to how children approached the exhibit. A constant queue at FF was an indication of its popularity. Typically, children were drawn to the ladder, and started to queue at the base of the ladder or move onto the ladder standing behind a child they might know who was using the hose (this occurred half as often as the other direction of swapping location). It was unusual for children to initially be drawn to the wheel or to queue at the wheel controller. Children often moved to the wheel controller after using the hose controller, unless the entire group was moving on. Patterns also included whole groups interchanging positions at one time. It was rare for companions to directly swap positions.

The next vignette shows one pattern of movement at GD, where a visitor disengages from interacting with the controllers at station 1 and starts to move up and down the length of the exhibit. The group consists of Dad, daughter Casey (age 7) and son Bill (age 11). The vignette starts after the group has used the exhibit twice. Up until this point Bill has been interacting at station 1, adding coal and water with the controllers.

\subsubsection{Vignette 3.}

Casey who is standing at station 2 attracts Bill and Dads attention (who are at station 1) asking them "see it's working! It's going up" (Figure 7 left). This attracts their attention to the other end of the exhibit. Moving towards Casey at station 2 Bill responds "what" (Figure 7 left). Dad, Bill and Casey all look at the working mechanical model for a moment at the far end of the exhibit.

Casey tells them "add more at the top". Bill moves back to station 1 where he can add more water. Bill starts to add water, turning the wheel at station 1 .

Holding on the wheel at station 1, Bill leans to try and see the other end while asking "Dad look at the pressure, Dad look at the pressure going up" (Figure 7 right). 

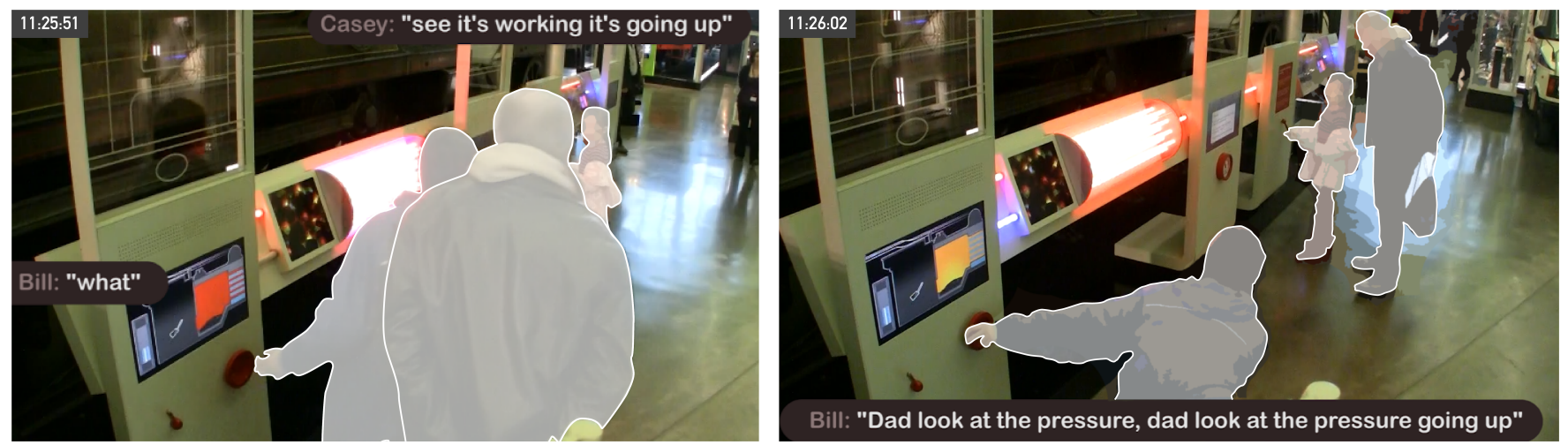

Figure 7: Dad, Bill \& Casey work together
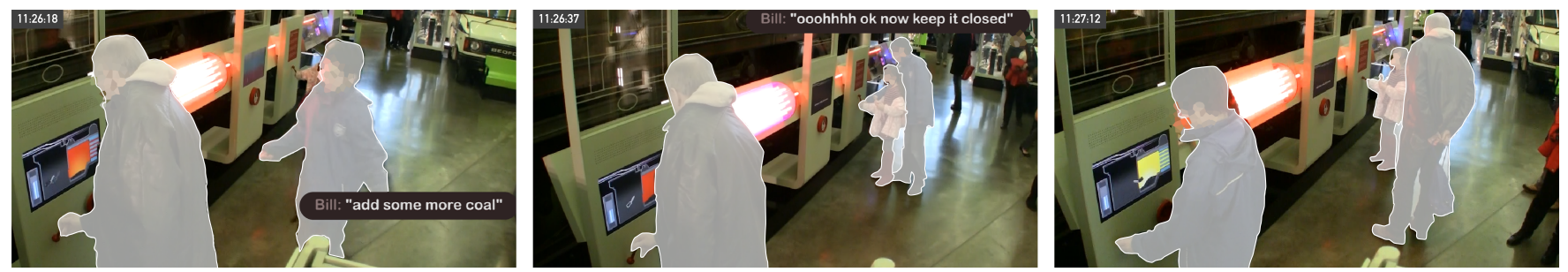

Figure 8: Stepping back \& guiding the interaction

Watching the pressure gauge Dad responds "if it goes too high it'll burst". Dad moves to stand behind Bill at station 1, watching what they are doing.

Bill starts to move away from station 1 to see the rest of the exhibit. Bill explains to Casey what he thinks she should be doing at station 2. While Bill moves away from station 1, Dad moves towards the controllers at station 1 and starts to use them.

Dad starts to add coal and water using the wheel and lever at station 1. Bill now starts to move back and forth between the two ends of the exhibit, monitoring what is happening and directing the others in what to do "add some more coal" (Figure 8 left).

Bill moves between guiding Dad's interaction with the exhibit, dipping in to use the controllers himself at station 1 with Dad and at station 2 with Casey (Figure 8 middle), and then stepping back again.

Bill returns to station 1, taking over from Dad. Dad steps back, moving towards the other end of the exhibit, swapping positions with Bill.

Then Dad starts moving between parts of the exhibit himself, guiding the kids' interaction "it said add water" (Figure 8 right).

The vignette shows a situation where a visitor (Bill) disengages from interacting with the controllers at station 1 and moves to view the rest of the exhibit (physical and functional distribution). The act of stepping back from interacting tended to prompt a number of interesting social behaviors such as: 1) companions shared the interaction with the same controllers back and forth at station 1,2) instead of constantly interacting with the exhibit themselves (temporal distribution), visitors mediate and guide their companions' interaction with the exhibit (indirect verbal distribution) and 3) companions were listening and referring to each other while interacting. In the vignette, we see Bill still actively participating, even when he is not using a controller. Visitors were observed choosing to step back and disengage from a controller, but remain active, participating in a key role for the overall interaction. This is an important pattern with regard to social events, even if the pattern was only observed for less than half of the groups.

The next vignette describes a group of six children and two adults interacting with the FF exhibit. The vignette shows two movement patterns. Firstly, as one individual leaves the hose controller, the whole group move positions. Secondly, when individuals finished using the hose controller, they typically stepped down the ladder to start using the wheel controller.

\subsubsection{Vignette 4.}

The vignette shows child 2 using the hose (Figure 9 left) and then moving to the wheel (Figure 9 right) as child 3 moves ahead to use the hose. The same pattern plays out for child 3 (Figures 9 right $\& 10$ left) and child 4 (Figure 9 right 10 right). After using the hose, they move to the wheel (physical and functional distribution). Exchanging positions appeared to be prompted by a child moving down the ladder and gradually walking to the wheel, displacing the wheel operator. In the meantime, another child would take their place at the hose. These movements and swapping of positions and controllers were a way companions shared interaction with the exhibit. As children moved between controllers, control passed between many members of the group but they all remained at the exhibit in different positions, including on the ladder. Movement thus played a crucial role in companions' shared social interactions. 

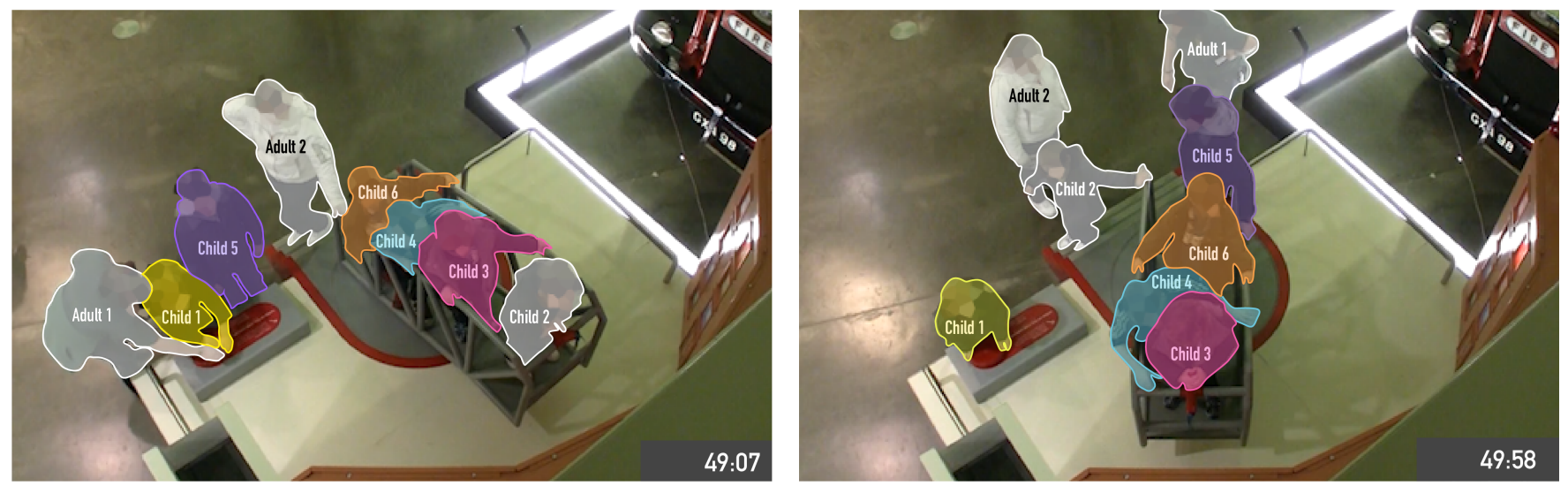

Figure 9: Movement patterns between group members
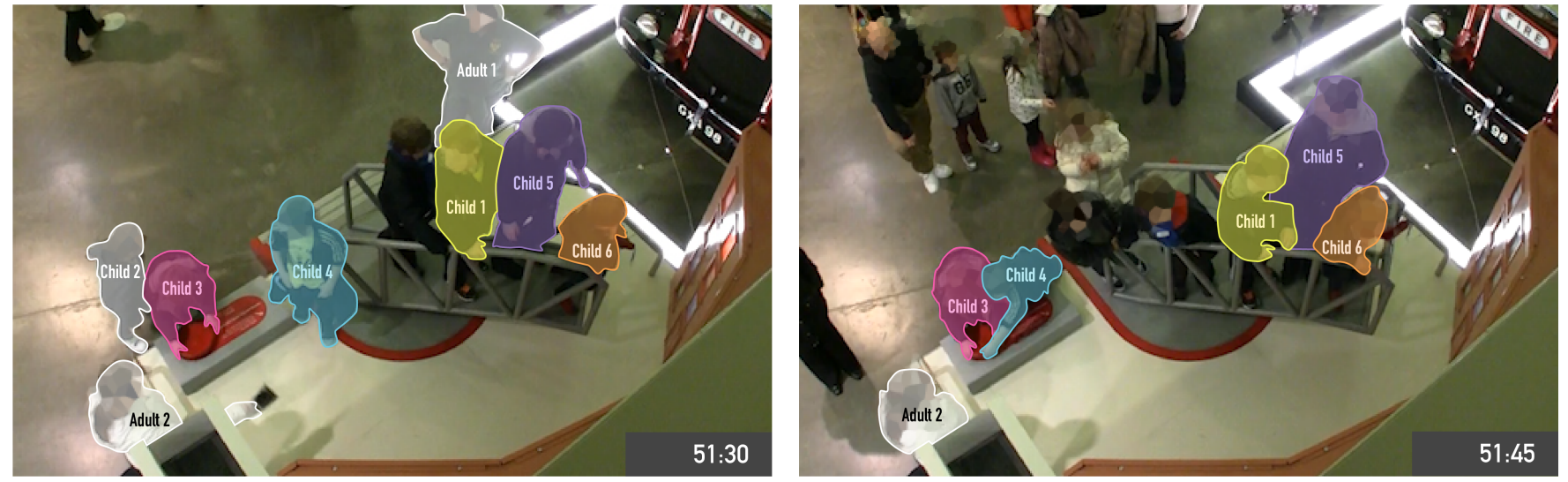

Figure 10: Continued movement patterns between group members

Such social activity was often linked with handing over control, sharing control and supporting companions using the hose.

The reverse movement of children interacting with the wheel controller first and then exchanging or swapping positions was less frequent. Companions in these groups also interacted with both controllers and supported each other on the ladder. These patterns indicate visitors were drawn to certain parts of the exhibit, suggesting desirable positions (the ladder) which most visitors moved towards.

\subsection{Adult Participation}

Another observation concerned physical participation of adults with controllers. Adults participated in the interaction at both exhibits by verbally supporting groups' interaction, but also engaged in physical interaction with controllers.

At the GD exhibit, for less than half of the groups, parents participated in the activity by physically interacting with the exhibit along with their children. One of these situations was shown in Vignette 3 where Bill disengaged from interaction at station 1 (physical and functional distribution) and began verbally orchestrating the interaction of his companions with the exhibit (indirect verbal distribution). Upon Bill stepping back from physical interaction,
Dad stepped forward to physically interact at station 1. Bill stepping back opened up an opportunity for Dad to participate in the activity. While parents' physical interaction was not constant and only happened for some groups at GD, the way that groups interacted with the exhibit and with each other created opportunities for adults beyond mere verbal involvement to physically participate in interaction. At the same time, children were able to take a leading role, guiding others in their interaction with the exhibit.

At FF, adult participation predominantly consisted of turning the ladder their children were on via the wheel controller (physical and functional distribution) at certain moments (temporal distribution). For more than half of observed groups with parents using the wheel controller, they were either more than half of the time active at the exhibit or repeatedly dipping in to use the wheel controller. As described in section 4.2 , children were typically drawn to the ladder. Unlike children, parents typically immediately moved to the wheel at FF. This filtering of children to the ladder and away from the wheel gave parents the opportunity to take an assistive role in steering the ladder via the wheel controller (physical and functional distribution). In some cases, parents would override young children's use of the wheel so they could move the ladder, likely for the children on the ladder requesting where to move 
it to, as described in vignette 2. Parents also stepped in at the wheel controller when children swapped positions, presumably to hold onto it for their child coming down from the hose controller. All groups except for one had at least one adult who physically interacted with the exhibit. For groups with only one child, parents would use the wheel controller to move the ladder while their child was on the ladder using the hose.

\section{DISCUSSION}

Our study analyzed interactions at two exhibits that share the criteria of relying on physical interaction and teamwork, but differ on other aspects (e.g. complexity of the task, target age group). This enables us to compare and to identify how shared aspects of the exhibit design have similar effects on group interaction. Our work specifically focuses on the social interaction between companions at the two exhibits. Here we consider the broader question of the role that features of the exhibit play, specifically, the distribution of control between companions. We discuss three overarching foci in the discussion section. Firstly, we suggest that the configuration of exhibits (in particular by distributing control between companions differently) influenced social behaviors. We reflect on how distributed control prompts alternating sequential actions and interactions within groups and creates a situation where visitors rely upon their companions to interact with an exhibit. Secondly, we highlight some benefits of reliance on companions and of alternating sequential interaction, in particular, visitors paying attention to each other and not just focusing on themselves. Finally, we discuss how the configurations of distributed control offered alternative positions and perspectives to companions and the value this had in supporting co-experience and fostering the inclusion of companions into the activity.

\subsection{Distribution of Control Between Companions}

Prior research has shown that the configuration of public installations can shape group behavior patterns [30, 56, 66]. Here, we have provided a systematic analysis and reflection of the social and shared interactions at two exhibits, focusing on the notion that different configurations distribute control in different ways. Our analysis revealed that the distribution of control was a key factor for how visitors' social and shared interactions unfolded when interacting with exhibits. The exhibits had the following commonalities in relation to their setup and resulting distribution of control:

- both exhibits had at least two physical tangible controllers (physical distribution)

- controllers were physically separated from each other (physical distribution)

- the exhibits were distributed over a large area of at least 2 square meters (physical distribution)

- controllers had different functions, affecting different parts of the exhibit both digital and physically (functional distribution).

- during the activity, at certain times, it was appropriate or inappropriate to use specific controllers, thus distributing control over time (temporal distribution)
- in addition, at GD, there was an element of indirect control exerted via verbal guidance from the information on screen 2.

We therefore suggest that there are four mechanisms of how control can be distributed:

- functional distribution of control

- temporal distribution of control

- physical distribution of control

- secondary indirect verbal distribution of control

While this list of mechanisms may not be all-encompassing, we hope these to be useful both for evaluation and as design sensitivity. In the following, we reflect on the presence of these mechanisms at exhibits in relation to the structure of companion's interaction and interdependent relationships.

\subsubsection{Alternating Sequential Action.}

The way in which control was distributed either physically, functionally, temporally and/or through secondary verbal guidance between members of a group resulted in companions engaging in alternating sequential action. 'Alternating' here refers to sequential interactions between people, for example, using resources in a back and forth pattern between companions. Alternating actions allowed groups to share physical interaction, to have mutual involvement in activity, and fostered social interactions between companions. For example, visitors waited to use particular controllers at appropriate moments (temporal distribution) such as the hose to FF to put out a fire after a companion used the wheel to move the ladder (physical and functional distribution). At GD, visitors used specific controllers based on guiding information relayed to them by companions viewing the instructions on screen 2 (indirect verbal distribution). At both exhibits, visitors turned their attention towards companions in relation to these patterns of alternating sequential actions. Fostering sequential actions between companions that are spread out over the course of the interaction (temporal distribution) helps to mitigate against individuals focusing all of their attention on their own interaction or dominating interaction with the exhibit. Similarly, Block et al. [8] found there are benefits when visitors take turns to interact at exhibits, engaging in sequential interaction. For example, people spent longer at exhibits and engaged more with the topic, narrative and content [8].

\subsubsection{Relying upon Companions \& Opportunities to Support Each} Other.

In addition to leading to alternating sequential actions among companions, distributed control configurations created a dependency between companions interacting with the exhibits. Interdependency during collaborative activities has previously been noted for its benefits in reducing conflicts and users explaining more what they want to do [68]. Creating dependency upon companions has been recognised to foster social interaction and support bonding $[56,68]$. However, there has been limited implementation of this mechanism and its benefits in the context of multi-user museum interactive exhibits [8]. Many interactive multi-user exhibits resort to providing multiple controllers, thereby dividing control in a way that prompts companions independent parallel interaction. Furthermore, multi-user interactive exhibits often involve competition [36]. Even though many exhibits presented in the background 
literature foster a dependent relationship between companions [30] and become unusable without a companion with whom to share the interaction $[60,66]$, few of these studies explicitly highlight the design strategy of creating a reliance upon companions as an important consideration when designing to encourage social interaction around interactive exhibits [3, 68].

The dependency relationship resonates with Benford et al.'s [7] categorisation of interaction with systems in terms of whether they enforce, encourage or enable collaboration. Both GD and FF sit on the 'enforcing collaboration' end of the scale as it is nearly impossible to use these alone, without relying on companions' collaboration. The controllers were physically separated (physical distribution) and manipulated different parts of the exhibit (functional distribution), but importantly, the functional and temporal use of controllers interlinked companions' activities. The way companions' activities are interlinked creates a situation where companions rely upon each other. Visitors couldn't use the fire hose effectively at FF without a companion using the controller (wheel) they had access to first. At GD, for visitors to effectively use the controllers at station 1 they were reliant on the guiding information displayed at station 2, where a companion was often located. In addition, the pressure lever at GD wasn't effective until controllers located away from it were used to build up the pressure. Control was distributed temporally over the course of the interaction, functionally between the use of differing resources accessible to different members of the group, physically by providing multiple digital resources and spatially separating them and through secondary indirect control providing guiding information as a tool to support effective interaction.

The distribution of control here created reliance on companions, sparking social interaction where visitors coordinated actions, guided each other's interaction and turned their attention towards companions while using the exhibits. In the context of museums, children often try to interact alone rather than sharing the activity $[7,34]$. Collaboration and sharing can be difficult, especially for younger children [58]. Fostering dependency on companions could be a suitable tactic for facilitating shared interaction and social interactions for family groups, helping children to learn sharing skills, depending upon their siblings or friends and offers opportunities for parents to be involved in physical interaction with the exhibit alongside their children, instead of being limited to solely verbal participation. This then enhances co-experiences.

A benefit of the dependent relationship resulting from distribution of control was that it presented opportunities for companions to support each other. Supporting others' interaction at GD involved relaying information so that companions could interact effectively; at FF support by companions involved moving the ladder into position. It wasn't always parents taking on this supportive role but siblings and children also supported each other. For groups with only one child, the reliance on the wheel controller at FF facilitated a shared activity with parents who moved the ladder for their child.

It is very rare for interactive museum exhibits to explicitly utilize the strategy of requiring users to collaborate and rely upon each other. Benefits and limitations regarding sequential versus simultaneous interaction have previously been debated [8] and are important to highlight here. At the two exhibits we studied, companions' sequential interaction involved turning their attention to each other, aligning actions and guiding each other, thereby supporting each other.

\subsection{A Focus Beyond Oneself}

A key challenge in supporting visitors' social interactions with companions at interactive exhibits, is that frequently their focus is on their own personal interaction [7, 46]. Exhibits can exacerbate this by demanding constant attention and action from individuals [36]. This leaves little time or capacity for companions to pay attention to each other. In contrast, although the exhibits we studied were highly interactive, we found visitors alternated their focus between their own interaction and their companions, expanding their focus beyond themselves. We suggest this is underpinned by the configuration of distributed control between members of a group which resulted in alternating sequential interaction and interdependency discussed in the previous section.

Museum exhibits should support both social and individual experiences [19] but often multi-user interactive exhibits lead visitors to focus on their individual interactions [57], even if the digital content rewards collaborative actions [7]. At the studied exhibits, visitors frequently shifted their attention between their own interaction and that of their companions. Visitors turned their attention to their companions, guiding each other and aligning their actions. The distribution of interactive resources, inputs and outputs, between companions, along with prompting specific moments to use different resources and a connection between resources, encouraged visitors to balance attention between their own interaction with the exhibit and their companions. For example, at GD, visitors were active at station 1 while simultaneously listening out for and referring to their companions for the guiding information visible at station 2. At FF, individuals interacting with the wheel or hose controller focused not only on their own controller but also at their companions' use of the hose or wheel controller at different moments. The temporal distribution of control is a pivotal factor here. Individual interaction is temporarily paused and there is a shift of control to a companion, shifting attention to them.

It is unusual to observe visitors who are in possession of a controller and directly face digital content to turn their attention away towards other people (which happened often at FF) or to step away from controllers, giving up control to companions in order to see the rest of the exhibits or to oversee companions' interactions (which happened at GD). These behaviors support bonding and socially connecting companions. We suggest such behaviors were encouraged by the distribution of control, interconnecting different parts of the exhibit and creating reliance between companions.

\subsection{Alternative Positions and Perspectives}

In relation to how control was configured at the exhibits, we here discuss how this offered alternative positions and perspectives for companions and the social value offered, such as supporting coexperience and fostering inclusion of companions into the activity.

\subsubsection{Alternative Perspectives supporting Co-experience.}

Within the context of HCI models, the social dimension of the user experience can be understood as 'co-experience' [6]. " $\mathrm{Co}$ experience is a process where participants together contribute to the 
shared experience" [6]. There are different ways companions can share experiences together. At a traditional museum display case, co-experience can mean sharing opinions [47] or moving to see what others see [62]. At both exhibits discussed here, the physical arrangement and separation of tangible controllers and a desire to use a different controller after handing over control, appeared to stimulate movements within groups, and led companions to exchange positions. The social experience was not based only on sharing the interaction but on swapping positions and experiencing different perspectives. Rather than duplicating the same interactive elements for companions to experience in parallel [16, 57], having distributed complementary resources enables companions to share the interaction from different perspectives. It also provided an incentive for visitors to move to other positions at the exhibit which, as described in section 4.2 , fosters social interaction and shared interaction. Moving to other positions enabled companions to share different perspectives of the same activity and fostered children to support each other in interacting with the exhibit. In addition, companions who interacted at both stations at FF spent longer as a group at the exhibit than the groups who didn't try out both perspectives.

\subsubsection{Desirable Positions and Understated Positions of Control.}

The observed behaviors indicate there were desirable positions and 'understated' positions of control. Both exhibits appeared to have a primary 'desirable' position visitors were drawn to. In the case of FF, visitors were mostly drawn to the ladder to use the hose controller (probably as this is where one actively fights the fire). At GD, visitors were typically drawn to station 1 with its two controllers for coal and water. However, both exhibits had essential additional positions of control which appeared understated (less in focus). At FF, the wheel controller was essential to use the hose effectively and at GD, guiding information from screen 2 enabled visitors to use the controllers at station 1 successfully.

These desirable positions and understated positions of control prompted patterns of movement, described in section 4.2. The patterns of moving between controllers show different members of a group being included in interaction after they hand over controllers to companions (section 4.2). Future designs could utilize the idea of a visually implied desirable position as a design tactic, attracting people to the apparently most desirable position. Yet, these can then include a secondary position of control that is understated, but vital for interaction at the primary desirable position. While using one part (the ladder and hose at FF or station 1 at GD) of the exhibit and understanding how it links to another part of the exhibit, a desire to move and experience other related parts is stimulated. Realising connections between different parts of an interactive exhibit can prompt visitors to interact socially with companions and with the exhibit, playfully making connections [30]. Potentially this could make it easier for visitors to move away from a primary controller and hand over control to companions, which is difficult for children [58]. At GD, the separation of key pieces of the exhibit appeared to prompt visitors to step back from the exhibit and move towards other parts of the exhibit, gaining an overview, often sparking changing positions with companions and handing over. Section 4.2 describes how some visitors at GD moved between interactive and active participation willingly, dipping in and out of interaction along with companions. The step back created an opportunity for others, including adults, to participate. This situation enables children to lead the group activity directing others what to do, rather than parents taking on this role.

At interactive exhibits children typically engage in physical interaction, rather than parents [20]. However, at both studied exhibits parents were included in the physical interactions. At FF, attracting children to one part of the exhibit gave parents the opportunity to be included in a physically interactive capacity at an understated secondary but powerful and supportive controller. Whereas at GD, it was moments where children stepped back from interacting that typically gave parents opportunity to join the physical interaction. While this may not seem a striking observation, at interactive museum exhibits, parents often facilitate children's interaction predominantly through verbal and non-interactive support [39, 53]. This seems a novel behavior in the museum context, given prior research has predominantly focused on children's physical interaction and there can be the perception that interactive exhibits are only intended for children, not for adults.

The patterns of moving and exchanging controllers highlights how exhibits can support members of a group being included in the interaction before and after handing over control of the most desirable controllers. Encouraging movements where visitors disengage from interaction could be a strong foundation to support sharing, handing over of control, sharing perspectives and to include parents in physical interaction with exhibits. Potentially, deprioritising key controllers or positions could open up opportunities for social shared interactions. We suggest that future designs explore the idea of making powerful or desirable positions appear undesirable (understated), so as to include companions in important physical interactions and to encourage visitors to move away from controllers and hand over control to companions.

\subsection{Why Is This Important}

The types of social interactions visitors have with their companions can be supported or hindered by the design of exhibits and interaction with exhibits. It is important to recognize the benefits and tradeoffs that interactive exhibits with particular interactional structures can offer for social interactions [30,57]. In the case studied here, the exhibits support social activities where visitors: focused beyond their personal interaction towards their companions' interaction; supported their companions; and engaged in sequential actions coordinating with companions.

Focusing on how control is distributed at interactive exhibits provides us new insights that can inform design and opens up opportunities for future research. When individuals engage with interactive technology, they tend to devote the majority of their attention and communication to the technology and overlook communicating with people around them. This is a common situation in museums when visitors use interactive exhibits. Distributing control of an exhibit among group members is one mechanism to foster shared interactions. As we have shown, there are several ways that distributed control can be implemented. How exactly distributed control is implemented can impact upon the social interactions that companions engage in while using the exhibit and how interaction with the exhibit is shared with a group. While some 
of these mechanisms are utilized in other contexts, such as game design [61] game design mechanisms do not always translate to a museum context. For instance, in museums, visitors often arrive and leave mid-way (see e.g. [69] ), typically there are no frequent ('expert') players, but on the other hand, there are other visitors waiting to interact. Basing installation design on video game patterns can thus result in exhibits that are not suited to the context. Moreover, on the museum floor, spatial-physical mechanisms of distribution of control can be utilized that are not available for classical video game design. Our work thus differs by identifying mechanisms that are directly relevant to the museum context.

It is still common to find museum installations that do not address groups, or where the attempt to do so failed, either not attracting visitors, or posing problems in aligning multiple peoples interactions successfully. The two installations studied here, in this regard are exceptions, in being successful examples for requiring collaboration from its users. Although prior research has developed design sensitivities regarding co-participation [30] and design principles for social engagement [57], there is a lack of well-established considerations designers can refer to concerning multiple distributed controllers. Our work contributes to establishing such design considerations to both inform design and open up opportunities for future research.

In the practitioner domain, evaluations of this kind are rare and the community largely depends on academic research to provide analysis, identify and name factors [18]. Hornecker and Ciolfi [37] were the first recently to provide a comprehensive overview, but do not describe mechanisms for control distribution. There is thus a gap in knowledge, where we contribute to understanding how the social dimension of the visit can be supported via distribution of control.

\section{CLOSING REMARKS}

Here, we have argued for an explicit design strategy in exhibit design to explore distributing control of digital content between companions for a number of reasons, including to support companions' social interactions. Given that one of the core elements of the museum experience is the social dimension, we focused on coparticipation and patterns of shared interaction. We here presented benefits of distributed control such as supporting co-experience, fostering the inclusion of companions into the activity and prompting companions to engage with each other socially while using an interactive exhibit. The latter is important to note as there is limited evidence of how to design to support both social interaction between companions and the inclusion of several people in the activity, in the context of museums $[4,56]$ and can often be associated with other tradeoffs $[30,66]$. Other benefits include adults' physical interaction along with children and shared experiences through different perspectives. A contribution of this research is the unpacking of how control is distributed by considering different strategies or mechanisms for doing so, that is, functional, temporal, physical and indirect means of distributing control.

While we presented possible benefits, there are also arguments against enforced collaboration. However, one of the purposes of museums and cultural heritage institutions is to provide visitors with a variety of experiences tending to their social, cultural and personal needs. With this in mind, we do not suggest that all interactive exhibits should configure control in this way but that it is one factor for interactive exhibits to consider if the museum wants to facilitate activities where companions support each other, fostering intergenerational physical interaction, that have parents included in the activity beyond only verbal participation, and group interaction which encourages visitors to turn their attention to their companions. Museums may want to provide a variety of interactive experiences involving social interaction. We suggest that in the cases we presented here, the distribution of control at exhibits underpinned activity which prompted and involved social interaction between companions.

A limitation of this research is the exclusion of the design agency's perspective and rationale behind the installations. Unfortunately, interviews with the exhibit designers were not possible. Our research unpacks the behavior and conduct of companions while they interact at interactive exhibits and is therefore based on observation from video analysis [11, 24, 25, 41]. Further research could investigate, for example, what visitors that interacted with the steam engine GD installation retained and learned, if the complex interaction posed too much of a challenge or was motivating for them, and how they subjectively experienced the group interaction. For the fire fighter installation, parents' perspective on the installation would be interesting.

In this paper, we presented findings from a video analysis of two museum installations which share characteristics in terms of requiring at least two users to participate and coordinate their actions via a physically distributed setup with several loci of control. We focused on families' interactions and social behavior. Detailed analysis unpacked the benefits of a distribution of control. We suggest that future research should investigate further the effect and differences between different types of distribution of control, of which we identified four, and that these may serve as design sensitivities for practical work in exhibit design.

\section{ACKNOWLEDGMENTS}

Special thanks to Glasgow Life, Glasgow Museums and all the staff at the Riverside Transport Museum, in particular David Scott, and Susie Ironside.

\section{REFERENCES}

[1] Sue Allen. 2003. Looking for learning in visitor talk: A methodological exploration. In Learning conversations in museums, Gaea Leinhardt and Kevin Crowley (Eds.). Routledge, London, New York, 265-309.

[2] David K Allison and Tom Gwaltney. 1991. How People Use Electronic Interactives: "Information Age-People, Information \& Technology". In International Cultural Heritage Informatics Meetings (Pittsburgh, Pennsylvania) (ichim91). Archives \& Museum Informatics, Pittsburgh, USA, 62-73. http://www.archimuse.com/ publishing/hypermedia/hypermedia.Ch9.pdf

[3] Alissa N. Antle, Alyssa F. Wise, Amanda Hall, Saba Nowroozi, Perry Tan, Jillian Warren, Rachael Eckersley, and Michelle Fan. 2013. Youtopia: A Collaborative, Tangible, Multi-Touch, Sustainability Learning Activity. In Proceedings of the 12th International Conference on Interaction Design and Children (New York, New York, USA) (IDC '13). Association for Computing Machinery, New York, NY, USA, 565-568. https://doi.org/10.1145/2485760.2485866

[4] Paul M. Aoki, Rebecca E. Grinter, Amy Hurst, Margaret H. Szymanski, James D. Thornton, and Allison Woodruff. 2002. Sotto Voce: Exploring the Interplay of Conversation and Mobile Audio Spaces. In Proceedings of the SIGCHI Conference on Human Factors in Computing Systems (Minneapolis, Minnesota, USA) (CHI '02). Association for Computing Machinery, New York, NY, USA, 431-438. https: //doi.org/10.1145/503376.503454 
[5] Chantal Barriault and David Pearson. 2010. Assessing exhibits for learning in science centers: A practical tool. Visitor Studies 13, 1 (April 2010), 90-106. https://doi.org/10.1080/10645571003618824

[6] Katja Battarbee. 2004. Co-experience: understanding user experiences in interaction. Aalto University, ISBN 9515581613. http://urn.fi/URN:ISBN:951-558-161-3

[7] Steve Benford, Benjamin B. Bederson, Karl-Petter Åkesson, Victor Bayon, Allison Druin, Pär Hansson, Juan Pablo Hourcade, Rob Ingram, Helen Neale, Claire O'Malley, Kristian T. Simsarian, Danaë Stanton, Yngve Sundblad, and Gustav Taxén. 2000. Designing Storytelling Technologies to Encouraging Collaboration between Young Children. In Proceedings of the SIGCHI Conference on Human Factors in Computing Systems (The Hague, The Netherlands) (CHI '00). Association for Computing Machinery, New York, NY, USA, 556-563. https://doi.org/10. $1145 / 332040.332502$

[8] Florian Block, James Hammerman, Michael Horn, Amy Spiegel, Jonathan Christiansen, Brenda Phillips, Judy Diamond, E. Margaret Evans, and Chia Shen. 2015. Fluid Grouping: Quantifying Group Engagement around Interactive Tabletop Exhibits in the Wild. In Proceedings of the 33rd Annual ACM Conference on Human Factors in Computing Systems (Seoul, Republic of Korea) (CHI '15). Association for Computing Machinery, New York, NY, USA, 867-876. https://doi.org/10.1145/2702123.2702231

[9] Florian Block, Michael S. Horn, Brenda Caldwell Phillips, Judy Diamond, E. Margaret Evans, and Chia Shen. 2012. The DeepTree exhibit: Visualizing the tree of life to facilitate informal learning. IEEE Transactions on Visualization and Computer Graphics 18, 12 (Dec. 2012), 2789-2798. https://doi.org/10.1109/TVCG.2012.272

[10] Minda Borun, Margaret Chambers, and Ann Cleghorn. 1996. Families are learning in science museums. Curator: The Museum fournal 39, 2 (May 1996), 123-138. https://doi.org/10.1111/j.2151-6952.1996.tb01084.x

[11] Virginia Braun and Victoria Clarke. 2006. Using thematic analysis in psychology. Qualitative research in psychology 3, 2 (July 2006), 77-101. https://doi.org/10. 1191/1478088706qp063oa

[12] Luigina Ciolfi and Liam J. Bannon. 2007. Designing hybrid places: merging interaction design, ubiquitous technologies and geographies of the museum space. CoDesign 3, 3 (June 2007), 159-180. https://doi.org/10.1080/15710880701524559

[13] Loraine Clarke and Eva Hornecker. 2013. Experience, Engagement and Social Interaction at a Steam Locomotive Multimodal Interactive Museum Exhibit. In CHI'13 Extended Abstracts on Human Factors in Computing Systems (Paris, France) (CHIEA '13). Association for Computing Machinery, New York, NY, USA, 613-618. https://doi.org/10.1145/2468356.2468464

[14] Kevin Crowley, Maureen A. Callanan, Jennifer L. Jipson, Jodi Galco, Karen Topping, and Jeff Shrager. 2001. Shared scientific thinking in everyday parent-child activity. Science Education 85, 6 (Oct. 2001), 712-732. https://doi.org/10.1002/sce. 1035

[15] Peter Dalsgaard and Christian Dindler. 2009. Peepholes as means of engagement in interaction design. In Proceedings of Nordes (Oslo, Norway) (Nordes 2009). Nordes, Norway. https://archive.nordes.org/index.php/n13/article/view/56

[16] Peter Dalsgaard, Christian Dindler, and Kim Halskov. 2011. Understanding the dynamics of engaging interaction in public spaces. In Human-Computer Interaction - INTERACT 2011. Springer, Berlin, Heidelberg, 212-229.

[17] Peter Dalsgaard and Kim Halskov. 2014. Tangible 3D Tabletops. ACM Interactions 21, 5 (Sept. 2014), 42-47. https://doi.org/10.1145/2658859

[18] Maurice Davies and Christian Heath. 2014. "Good" organisational reasons for "ineffectual" research: Evaluating summative evaluation of museums and galleries. Cultural Trends 23, 1 (Dec. 2014), 57-69. https://doi.org/10.1080/09548963.2014 862002

[19] Stéphane Debenedetti. 2003. Investigating the Role of Companions in the Art Museum Experience. International fournal of Arts Management 5, 3 (2003), 52-63. http://www.jstor.org/stable/41064797

[20] Judy Diamond. 1986. The behavior of family groups in science museums. Curator The Museum fournal 29, 2 (June 1986), 139-154. https://doi.org/10.1111/j.21516952.1986.tb01434.x

[21] Lynn D Dierking. 1989. The family museum experience: Implications from research. The fournal of Museum Education 14, 2 (1989), 9-11. http://www.jstor. $\mathrm{org} /$ stable $/ 40478807$

[22] Christian Dindler, Ole Sejer Iversen, and Peter Gall Krogh. 2011. Engagement through Mixed Modalities. ACM Interactions 18, 4 (July 2011), 34-39. https: //doi.org/10.1145/1978822.1978830

[23] John H Falk and Lynn D Dierking. 2013. The museum experience revisited. Left Coast Press, Walnut Creek, CA.

[24] Gregory Guest, Kathleen M MacQueen, and Emily E Namey. 2012. Introduction to applied thematic analysis. In Applied thematic analysis, Gregory Guest, Kathleen M MacQueen, and Emily E Namey (Eds.). SAGE Publications, Inc., California, USA, 3-20. https://dx.doi.org/10.4135/9781483384436.n1

[25] Christian Heath, Jon Hindmarsh, and Paul Luff. 2010. Video in qualitative research. Sage Publications Ltd, London, U.K.

[26] Christian Heath and Dirk vom Lehn. 2002. Misconstruing interactivity. In Proceedings of interactive Learning in Museums of Art and Design, V\&A Museum London. V\&A, London, U.K.
[27] Christian Heath and Dirk vom Lehn. 2008. Configuring 'Interactivity' - Enhancing Engagement in Science Centres and Museums. Social Studies of Science 38, 1 (Feb. 2008), 63-91. https://doi.org/10.1177/0306312707084152

[28] Christian Heath, Dirk vom Lehn, and Jonathan Osborne. 2005. Interaction and interactives: collaboration and participation with computer-based exhibits. Public Understanding of Science 14, 1 (Jan. 2005), 91-101. https://doi.org/10.1177/ 0963662505047343

[29] George E Hein. 2002. Learning in the Museum. Routledge, London, New York.

[30] Jon Hindmarsh, Christian Heath, Dirk vom Lehn, and Jason Cleverly. 2005. Creating assemblies in public environments: Social interaction, interactive exhibits and CSCW. Computer Supported Cooperative Work (CSCW) 14, 1 (Feb. 2005), 1-41. https://doi.org/10.1007/s10606-004-1814-8

[31] Uta Hinrichs. 2013. Open-Ended Explorations in Exhibition Spaces: A Case for Information Visualization and Large Direct-Touch Displays. University of Calgary, Canada, PRISM, Calgary, Candada. https://doi.org/10.11575/PRISM/10182

[32] Michael Horn, Zeina Atrash Leong, Florian Block, Judy Diamond, E. Margaret Evans, Brenda Phillips, and Chia Shen. 2012. Of BATs and APEs: An Interactive Tabletop Game for Natural History Museums. In Proceedings of the SIGCHI Conference on Human Factors in Computing Systems (Austin, Texas, USA) (CHI '12). Association for Computing Machinery, New York, NY, USA, 2059-2068. https://doi.org/10.1145/2207676.2208355

[33] Eva Hornecker. 2005. A design theme for tangible interaction: embodied facilitation. In Proceedings of the Ninth European Conference on Computer-Supported Cooperative Work (Paris, France) (ECSCW 2005). Springer, Dordrecht, Netherlands, 23-43.

[34] Eva Hornecker. 2008. "I don't understand it either, but it is cool" - visitor interactions with a multi-touch table in a museum. In 3rd IEEE International Workshop on Horizontal Interactive Human Computer Systems. IEEE, New Jersey, USA, 113-120. https://doi.org/10.1109/TABLETOP.2008.4660193

[35] Eva Hornecker. 2010. Interactions around a Contextually Embedded System. In Proceedings of the Fourth International Conference on Tangible, Embedded, and Embodied Interaction (TEI'10) (Cambridge, Massachusetts, USA) (TEI '10). Association for Computing Machinery, New York, NY, USA, 169-176. https: //doi.org/10.1145/1709886.1709916

[36] Eva Hornecker. 2016. The To-and-Fro of Sense Making: Supporting Users' Active Indexing in Museums. ACM Trans. Comput.-Hum. Interact. 23, 2, Article 10 (May 2016), 48 pages. https://doi.org/10.1145/2882785

[37] Eva Hornecker and Luigina Ciolfi. 2019. Human-Computer Interactions in $\mathrm{Mu}$ seums. Morgan \& Claypool Publishers, California, USA. i-171 pages. https: //doi.org/10.2200/S00901ED1V01Y201902HCI042

[38] Eva Hornecker, Paul Marshall, and Yvonne Rogers. 2007. From Entry to Access: How Shareability Comes About. In Proceedings of the 2007 Conference on Designing Pleasurable Products and Interfaces (DPPI'07) (DPPI '07). Association for Computing Machinery, New York, NY, USA, 328-342. https://doi.org/10.1145/ 1314161.1314191

[39] Eva Hornecker and Emma Nicol. 2012. What Do Lab-Based User Studies Tell Us about in-the-Wild Behavior? Insights from a Study of Museum Interactives. In Proceedings of the Designing Interactive Systems Conference (DIS'12) (DIS '12). Association for Computing Machinery, New York, NY, USA, 358-367. https: //doi.org/10.1145/2317956.2318010

[40] Eva Hornecker and Matthias Stifter. 2006. Digital Backpacking in the Museum with a SmartCard. In Proceedings of the 7th ACM SIGCHI New Zealand Chapter's International Conference on Computer-Human Interaction: Design Centered HCI (Christchurch, New Zealand) (CHINZ '06). Association for Computing Machinery, New York, NY, USA, 99-107. https://doi.org/10.1145/1152760.1152773

[41] Brigitte Jordan and Austin Henderson. 1995. Interaction analysis: Foundations and practice. The journal of the learning sciences 4, 1 (1995), 39-103. http: //www.jstor.org/stable/1466849

[42] Martin Kaltenbrunner. 2009. ReacTIVision and TUIO: A Tangible Tabletop Toolkit. In Proceedings of the ACM International Conference on Interactive Tabletops and Surfaces (ITS'09) (Banff, Alberta, Canada) (ITS '09). Association for Computing Machinery, New York, NY, USA, 9-16. https://doi.org/10.1145/1731903.1731906

[43] Lynda Kelly, Gillian Savage, Janette Griffin, and Susan Tonkin. 2004. Knowledge Quest: Australian families visit museums. Australian Museum, Sydney, Sydney, Australia.

[44] Hope Jensen Leichter, Karen Hensel, and Erik Larsen. 1989. Families and museums: Issues and perspectives. Marriage \& Family Review 13, 3-4 (1989), 15-50. https://doi.org/10.1300/J002v13n03_03

[45] Gaea Leinhardt and Kevin Crowley. 2002. Objects of learning, objects of talk: Changing minds in museums. In Perspectives on Object-Centered Learning in Museums, Scott G. Paris (Ed.). Routledge, New York, 301-324.

[46] Martin Ludvigsen. 2005. Designing for social use in public places - A conceptual framework of social interaction. In Proceedings of Designing Pleasurable Products Interfaces (DPPI'05). Association for Computing Machinery, New York, NY, USA, 389-408. https://doi.org/10.1145/1142405.1142459

[47] Kathleen McLean and Catherine McEver. 2004. Are We There Yet?: Conversations about Best Practices in Science Exhibition Development. Left Coast Press, Walnut Creek, CA. 
[48] Robin Meisner, Dirk vom Lehn, Christian Heath, Alex Burch, Ben Gammon, and Molly Reisman. 2007. Exhibiting performance: Co-participation in science centres and museums. International fournal of Science Education 29, 12 (Sept 2007), 1531-1555. https://doi.org/10.1080/09500690701494050

[49] Olufemi Omojola, E Rehmi Post, Matthew D Hancher, Yael Maguire, Ravikanth Pappu, Bernd Schoner, Peter R Russo, Richard Fletcher, and Neil Gershenfeld. 2000. An installation of interactive furniture. IBM Systems fournal 39, 3 \& 4 (2000), 861-879. https://doi.org/10.1147/sj.393.0861

[50] Menisha Patel, Christian Heath, Paul Luff, Dirk vom Lehn, and Jason Cleverly. 2016. Playing with words: creativity and interaction in museums and galleries. Museum Management and Curatorship 31, 1 (Dec. 2016), 69-86. https://doi.org/ 10.1080/09647775.2015.1102641

[51] Andrew J Pekarik, Zahava D Doering, and David A Karns. 1999. Exploring satisfying experiences in museums. Curator: The Museum fournal 42, 2 (April 1999), 152-173.

[52] Deborah L. Perry. 2012. What makes learning fun?: principles for the design of intrinsically motivating museum exhibits. Altamira Press, Lanham, MD.

[53] Barbara Piscitelli and Katrina Weier. 2002. Learning with, through, and about art: The role of social interactions. In Perspectives on object-centered learning in museums, Scott G. Paris (Ed.). Routledge, New York, USA, 121-151.

[54] Stuart Reeves, Steve Benford, Claire O’Malley, and Mike Fraser. 2005. Designing the Spectator Experience. In Proceedings of the SIGCHI Conference on Human Factors in Computing Systems (Portland, Oregon, USA) (CHI '05). Association for Computing Machinery, New York, NY, USA, 741-750. https://doi.org/10.1145/ 1054972.1055074

[55] Yvonne Rogers, Youn-kyung Lim, William R. Hazlewood, and Paul Marshall. 2009. Equal opportunities: Do shareable interfaces promote more group participation than single user displays? Human-Computer Interaction 24, 1-2 (April 2009), 79-116. https://doi.org/10.1080/07370020902739379

[56] Y. Rogers, S. Price, G. Fitzpatrick, R. Fleck, E. Harris, H. Smith, C. Randell, H Muller, C. O'Malley, D. Stanton, M. Thompson, and M. Weal. 2004. Ambient Wood: Designing New Forms of Digital Augmentation for Learning Outdoors. In Proceedings of the 2004 Conference on Interaction Design and Children (Maryland) (IDC '04). Association for Computing Machinery, New York, NY, USA, 3-10. https://doi.org/10.1145/1017833.1017834

[57] Scott S. Snibbe and Hayes S. Raffle. 2009. Social Immersive Media: Pursuing Best Practices for Multi-User Interactive Camera/Projector Exhibits. In Proceedings of the SIGCHI Conference on Human Factors in Computing Systems (Boston, MA USA) (CHI '09). Association for Computing Machinery, New York, NY, USA 1447-1456. https://doi.org/10.1145/1518701.1518920

[58] Danae Stanton, Victor Bayon, Helen Neale, Ahmed Ghali, Steve Benford, Sue Cobb, Rob Ingram, Claire O'Malley, John Wilson, and Tony Pridmore. 2001 Classroom Collaboration in the Design of Tangible Interfaces for Storytelling. In Proceedings of the SIGCHI Conference on Human Factors in Computing Systems (Seattle, Washington, USA) (CHI '01). Association for Computing Machinery, New York, NY, USA, 482-489. https://doi.org/10.1145/365024.365322

[59] Olov Ståhl, Anders Wallberg, Jonas Söderberg, Jan Humble, Lennart E. Fahlén, Adrian Bullock, and Jenny Lundberg. 2002. Information Exploration Using The Pond. In Proceedings of the 4th International Conference on Collaborative Virtual Environments (Bonn, Germany) (CVE '02). Association for Computing Machinery, New York, NY, USA, 72-79. https://doi.org/10.1145/571878.571890

[60] Robyn Taylor, John Bowers, Bettina Nissen, Gavin Wood, Qasim Chaudhry, Peter Wright, Lindsey Bruce, Sarah Glynn, Helen Mallinson, and Roy Bearpark. 2015. Making Magic: Designing for Open Interactions in Museum Settings. In Proceedings of the 2015 ACM SIGCHI Conference on Creativity and Cognition (Glasgow, United Kingdom) (C\&C '15). Association for Computing Machinery, New York, NY, USA, 313-322. https://doi.org/10.1145/2757226.2757241

[61] Katie Salen Tekinbas and Eric Zimmerman. 2003. Rules of play: game design fundamentals. MIT Press, Cambridge, Mass.

[62] Peter Tolmie, Steve Benford, Chris Greenhalgh, Tom Rodden, and Stuart Reeves 2014. Supporting Group Interactions in Museum Visiting. In Proceedings of the 17th ACM Conference on Computer Supported Cooperative Work \& Social Computing (CSCW'14) (Baltimore, Maryland, USA) (CSCW'14). Association for Computing Machinery, New York, NY, USA, 1049-1059. https://doi.org/10.1145/ 2531602.2531619

[63] Dirk vom Lehn and Christian Heath. 2005. Accounting for new technology in museum exhibitions. International fournal of Arts Management 7, 3 (2005), 11-21. http://www.jstor.org/stable/41064849

[64] Dirk vom Lehn and Christian Heath. 2007. Social interaction in museums and galleries: A note on video-based field studies. In Video and the Learning Sciences, Ricki Goldman, Roy Pea, Brigid Barron, and Sharon J. Derry (Eds.). Routledge / Taylor \& Francis, New York, USA, 287-301. https://doi.org/10.4324/9780203877258

[65] Dirk vom Lehn and Christian Heath. 2016. Action at the exhibit face: video and the analysis of social interaction in museums and galleries. Fournal of Marketing Management 32, 15-16 (June 2016), 1441-1457. https://doi.org/10.1080/0267257X 2016.1188846

[66] Ron Wakkary, Marek Hatala, Kevin Muise, Karen Tanenbaum, Greg Corness, Bardia Mohabbati, and Jim Budd. 2009. Kurio: A Museum Guide for Families.
In Proceedings of the 3rd International Conference on Tangible and Embedded Interaction. Association for Computing Machinery, New York, NY, USA, 215-222. https://doi.org/10.1145/1517664.1517712

[67] Kasia Warpas. 2014. Designing for Dream Spaces. ACM Interactions 21, 3 (May 2014), 66-69. https://doi.org/10.1145/2600020

[68] Alyssa Friend Wise, Alissa Nicole Antle, Jillian Warren, Aaron May, Min Fan, and Anna Macaranas. 2015. What kind of world do you want to live in? Positive interdependence and collaborative processes in the tangible tabletop land-use planning game Youtopia. In Proceedings of The Computer Supported Collaborative Learning (CSCL) 2015. International Society of the Learning Sciences, Inc.[ISLS]., Gothenburg, Sweden. https://repository.isls.org//handle/1/413

[69] Anna Xambó, Eva Hornecker, Paul Marshall, Sergi Jordà, Chris Dobbyn, and Robin Laney. 2013. Let's Jam the Reactable: Peer Learning during Musical Improvisation with a Tabletop Tangible Interface. ACM Trans. Comput.-Hum. Interact. 20, 6, Article 36 (Dec. 2013), 34 pages. https://doi.org/10.1145/2530541 